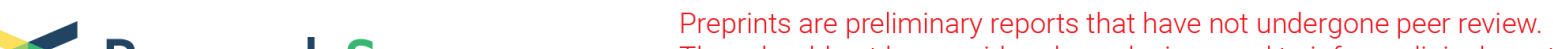

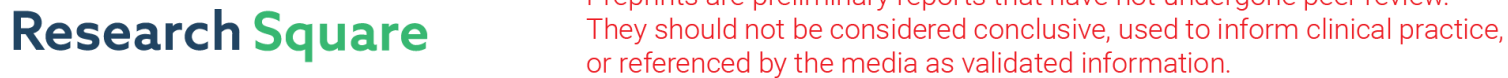

\section{Advanced Arc Plasma Synthesis of Biomorphic Silicon Carbide Using Charcoal and Silicon Dioxide in Air}

\section{Alexander Ya Pak}

Tomsk Polytechnic University: Nacional'nyj issledovatel'skij Tomskij politehniceskij universitet Kirill B Larionov ( $\triangle$ laryk070@gmail.com )

Tomsk Polytechnic University: Nacional'nyj issledovatel'skij Tomskij politehniceskij universitet Anastasia P Korchagina

Tomsk Polytechnic University: Nacional'nyj issledovatel'skij Tomskij politehniceskij universitet Tamara Yu. Yakich

Tomsk Polytechnic University: Nacional'nyj issledovatel'skij Tomskij politehniceskij universitet

\section{Stanislav A Yankovsky}

Tomsk Polytechnic University: Nacional'nyj issledovatel'skij Tomskij politehniceskij universitet

\section{Vladimir E Gubin}

Tomsk Polytechnic University: Nacional'nyj issledovatel'skij Tomskij politehniceskij universitet

\section{Konstantin V Slyusarskiy}

Tomsk Polytechnic University: Nacional'nyj issledovatel'skij Tomskij politehniceskij universitet

\section{Alexander A Gromov}

NUST MISIS: Nacional'nyj issledovatel'skij tehnologiceskij universitet MISiS

\section{Research Article}

Keywords: silicon carbide, biochar, silicon dioxide, electric arc synthesis, plasma, SPS

Posted Date: April 7th, 2021

DOI: https://doi.org/10.21203/rs.3.rs-335725/v1

License: (c) (1) This work is licensed under a Creative Commons Attribution 4.0 International License. Read Full License

Version of Record: A version of this preprint was published at Waste and Biomass Valorization on July 14th, 2021. See the published version at https://doi.org/10.1007/s12649-021-01517-8. 


\section{Abstract}

The paper presents the results of experimental studies on the advanced synthesis method for a cubic phase of silicon carbide using charcoal and silicon dioxide as precursors. The charcoal used for the synthesis was obtained by steam pyrolysis of wood wastes (sawdust). It was found that the arc synthesis could be executed in air due to the protective $\mathrm{CO}$ and $\mathrm{CO}_{2}$ environment formation by charcoal oxidation. With an increase of the amount of supplied energy by direct current arc plasma synthesis, the products of two crystalline phases were formed: graphite and cubic phase of silicon carbide. The phase of silicon carbide was extracted from the synthesis product by its annealing in air at $850{ }^{\circ} \mathrm{C}$. The resulting cubic SiC phase was characterized by an elementary cell parameter of $4.359 \AA$. According to the data of scanning electron microscopy, the morphology of crystals obtained is common for the biomorphic silicon carbide which was identified in the synthesis product. The ceramics synthesized by spark plasma sintering from the obtained material was characterized by a density of $\sim 2.0 \mathrm{~g} / \mathrm{cm}^{3}$.

\section{Statement Of Novelty}

For the first time the ceramics sample based on silicon carbide synthesized using biochar and silicon oxide via vacuumless electroarc method was obtained.

\section{Introduction}

Wastes from the wood are a renewable raw material for processing and further application for charcoal production. In turn, charcoal is a raw material for refractory materials obtaining based on metal and nonmetal carbides [1]. The use of charcoal for the production of metal and nonmetal carbides provides the synthesis with renewable, environmentally friendly raw materials. Additionally, the microstructure of charcoal could affect the morphology of the synthesis product, including the so-called "biomorphic" structure (structure with signs of the morphology of a living organism) of the material. In particular, such porous biomorphic materials can be used to solve various problems, for example, to create hightemperature filters. A large number of types of wood and other biomass, as well as its waste, allows the application of feedstock for the synthesis of the carbides of metals and non-metals with different shape and size of pores and channels, as well as with different physical and mechanical characteristics. In this case, it is possible to involve organic waste in the technological cycle of carbide production. Thus, the use of charcoal as a raw material for the synthesis of metal and non-metal carbides is an important direction of the scientific development in field of synthesis methods and the application of refractory carbides. A silicon carbide is the most studied among them as a material with an important set of properties, such as the resistance to oxidation, high hardness and relatively low density [2]. $\mathrm{SiC}$ is used in the aerospace industry, medicine, and other fields [3-4]. The synthesis of silicon carbide using various types of wood has already been studied for a beech, an oak, a sapele, a maple, a pine, and a linden [5-11]. A variety of morphological features of natural precursors provides almost unlimited implementation of the synthesis of ceramic materials with different morphological characteristics and, accordingly, properties [12-14]. The synthesis of silicon carbide using wood as an initial material is often carried out in two stages: in the first 
stage, the wood is pyrolized to produce charcoal. At the second stage its infiltration is carried out with a silicon melt or vapor and with the formation of SiC [1, 15-17]. A well-known method for the synthesis of carbide with a biomorphic structure is a sol - gel [18-19]. Despite of progress in this area, methods for silicon carbide synthesis using charcoal are still undeveloped. Among the disadvantages of the available methods, the following features could be distinguished: the long duration of the synthesis process, the need for prolonged infiltration of the initial biochar, the necessity to create an inert atmosphere for the synthesis process, the uneven distribution of the initial components and the complexity of the morphology controlling of the obtained particles. Accordingly, the development of new methods for the synthesis of silicon carbide using charcoal is an important task.

A well-known approach to produce silicon carbide powders is a usage of an electric arc. Arc discharge plasma provides high (on the order of several thousand degrees) temperatures in the reaction zone which is suitable for the synthesis of silicon carbide [20-22]. Usually the synthesis takes place in an inert gas atmosphere in a closed reactor. However, a group of vacuum-free electric arc methods has appeared recently. In our previous works the synthesis of silicon and tungsten carbides in the plasma of a DC arc discharge in air [23] was executed. This synthesis method application was possible because of selfshielding of the reaction zone by formed carbon monoxide and dioxide [24]. Thus, air cannot oxidize the obtained reaction products until they became cold and the oxidation reaction rate achieved a negligibly low value. This synthesis technique is simplified compared to the one assumed arc reactor construction with a vacuum pump, closed chamber and the entire vacuum-gas system of the reactor. Thus, the cost of this synthesis method is lower in general and the productivity of an open-type DC electric arc reactors is higher [25-27].

In the present work the electric arc synthesis of the cubic phase of silicon carbide in air has been implemented using charcoal obtained from the wood waste (sawdust) and silicon dioxide. The paper presents results of a study of the characteristics of synthesis product versus initial parameters of the process: the duration of arc discharge, the ratio of carbon to silicon dioxide in the initial composition. A powder of silicon carbide with biomorphic structure was obtained, which was then sintered by the method of spark plasma sintering. As a result, ceramic samples of silicon carbide with a density of $\sim 2.0 \mathrm{~g} / \mathrm{cm}^{3}$ was obtained.

\section{Materials And Methods}

\subsection{Biochar obtaining from wood wastes}

The biochar was obtained because of steam gasification of waste from a wood processing enterprise, pine sawdust. The process was carried out at superheated steam temperature of $400{ }^{\circ} \mathrm{C}$ with a steam flow rate of $1 \mathrm{~kg} / \mathrm{h}$. The process was carried out for 0.5 hours. The mass of the biochar residue was 28 wt. \% in relation to the initial mass of sawdust. The gasification product was ground in a drum mill in the following grinding mode: the ratio of the mass of grinding balls to the material was 1:1 and the grinding time was 8 hours. After grinding the screening was performed to obtain a powder fraction with a particle 
size $<200 \mu \mathrm{m}$. The elemental composition of biochar and its ash residue were determined using a Flash 2000 CHNS elemental analyzer (Thermo Fisher Scientific, USA) and the iCAP 6300 Duo inductively coupled plasma optical emission spectrometer (Thermo Scientific, USA), respectively. The specific surface area was determined using an ASAP 2400 specific surface area analyzer (Micromeritics, USA).

\subsection{Electric arc discharge synthesis}

Electric arc synthesis was carried out in an open air [23-24]. A direct current energy source with a maximum operating current of $220 \mathrm{~A}$ was used. An anode (graphite rod) and a cathode (graphite crucible) were connected to the power source. A mixture of reagents was placed in the cathode cavity: biochar produced from sawdust with particles of $<200 \mu \mathrm{m}$ with an amorphous structure and an amorphous $\mathrm{SiO}_{2}$ with particle size $<20 \mathrm{~nm}$. A gel was prepared from the particles of silicon dioxide preliminarily: $15 \mathrm{ml}$ of water and biochar powder were added to $1 \mathrm{~g}$ of silicon dioxide. The resulting gel was stored at room temperature in a vacuum chamber for 2 hours at a pressure $<0.01 \mathrm{MPa}$ to remove air. The resulting powder was dried in a corundum crucible in an oven at $200^{\circ} \mathrm{C}$ for one hour in air. Then the powder was loaded into the cathode cavity for the arc treatment. A maximum current up to $220 \mathrm{~A}$ (power density up to $\sim 19 \mathrm{~W} / \mathrm{mm}^{2}$, arc voltage $\sim 30 \mathrm{~V}$ ) was used which added more energy into the system for a time given. Three series of parallel experiments were carried out:

1. The duration of the synthesis process was varied from $5 \mathrm{~s}$ to $25 \mathrm{~s}$ (with a $5 \mathrm{~s}$ step). See supplementary video V1 (color image with temperature distribution) and V2 (video image).

2. The mass ratio of $\mathrm{SiO}_{2}: \mathrm{C}$ was varied: $3: 1,2: 1,1: 1$ and $1: 2$.

3. The synthesis was carried out for equal conditions in order to accumulate a sufficient amount of material for its subsequent enrichment and sintering.

\subsection{Analytical methods}

The synthesized materials were analyzed by X-ray diffractometry (Shimadzu XRD 7000s, CuKa radiation). The X-ray patterns were analyzed using standard X-ray diffractometer software (PC Suit XRD-6100/7000 Ver. 7.00: main). In particular, a component of the program for the analysis of the crystallinity degree (XRD: Crystallinity) was used. To carry out a qualitative X-ray phase analysis, the PDF4+ database was used. The quantitative analysis was carried out on the basis of the integrated intensity of the diffraction maximums.

Samples were studied under a TESCAN VEGA 3 SBU scanning electron microscope (SEM) and an OXFORD X-Max 50 energy-dispersive adapter (EDS) with a 10-20 kV accelerating voltage, specimen current of $12 \mathrm{nA}$, and a spot diameter of approximately $2 \mu \mathrm{m}$. The scanning electron microscope Hitachi TM 3000 was used for SEM as well.

The study of thermal decomposition (oxidation) of the obtained samples was carried out using a differential scanning calorimetry and thermogravimetry (DSC/TG/DTG) Netzsch STA 449 F3 Jupiter (Netzsch, Germany). The analysis was carried out at a heating rate of $10^{\circ} \mathrm{C} / \mathrm{min}$ in corundum crucibles 
with perforated lids in the temperature range from room temperature to $1200^{\circ} \mathrm{C}$. Powdery samples with a mass of $\sim 20 \mathrm{mg}$ were analyzed in air. The gas flow rate was $150 \mathrm{ml} / \mathrm{min}$ (air) and $10 \mathrm{ml} / \mathrm{min}$ (nitrogen). In the latter case, nitrogen was used as a shielding gas to ensure reliable operation of the analyzer and the correct recording of the data obtained. All DTA-TG experiments were carried out under atmospheric pressure. A comparative assessment of the parameters of the oxidation process was carried out on the basis of temperature, time and rate of the oxidation reaction calculated graphically using TG, DTG and DSC curves.

The synthesized powdery material was annealed in an atmospheric furnace (EKSP 10, Russia) to purify the synthesized silicon carbide phase. As-synthesized powders were placed in a mullite boat and heated up to $850^{\circ} \mathrm{C}$ at $25^{\circ} \mathrm{C} / \mathrm{min}$ heating rate. The powders were kept at this temperature for 2 hours. The obtained material after cooling was collected for further research and sintering.

Sintering of the obtained material was carried out in the SPS-10-4 system of spark plasma sintering (Advanced Technologies) at an axial pressure of $10 \mathrm{MPa}$ and a temperature of $1800^{\circ} \mathrm{C}$ for 10 minutes in an argon atmosphere. The ceramic samples obtained were processed for further research, in particular, on the surface microstructure. The samples were ground and then polished using Forcipol $1 \mathrm{~V}$ grinding and polishing machine via diamond discs with a $54 \mu \mathrm{m}, 18 \mu \mathrm{m}, 6 \mu \mathrm{m}, 3 \mu \mathrm{m}$ roughness and polishing cloths with diamond suspensions with abrasives with an average particle size of $6 \mu \mathrm{m}, 3 \mu \mathrm{m}, 1 \mu \mathrm{m}, 0.25$ $\mu \mathrm{m}$.

\section{Results And Discussion}

\subsection{Characteristics of biochar}

The technical characteristics and elemental composition for the $\mathrm{C}, \mathrm{H}, \mathrm{N}, \mathrm{S}, \mathrm{O}$ elements of the produced biochar are presented in Table 1. The sample of biochar obtained because of steam gasification was characterized by a relatively high value of the volatile substances content (about $32 \mathrm{wt} . \%$ ) and a relatively low ash content (about $1 \mathrm{wt}$.\%). The high value of the adsorbed moisture content could be caused by the activation of pore structure of carbon samples during the steam treatment of initial pine sawdust. Also, this sample was characterized by high oxygen content and the absence of sulfur, which is typical for products of the wood waste thermal processing.

Table 1 Technical characteristics of the obtained biochar (Flash 2000 CHNS) 


\begin{tabular}{|ll|}
\hline Parameter & Value \\
\hline Moisture content, wt.\% & 5.1 \\
\hline Ash content, wt.\% & 1.1 \\
\hline Volatiles content, wt.\% & 31.8 \\
\hline Net calorific value, MJ/kg & 28.1 \\
\hline Specific surface area, $\mathrm{m}^{2} / \mathrm{g}$ & 0.008 \\
\hline Element composition, wt. \% & \\
\hline C & 76.0 \\
\hline H & 3.3 \\
\hline $\mathrm{N}$ & 0.2 \\
\hline $\mathrm{S}$ & 0 \\
\hline O & 19.4 \\
\hline
\end{tabular}

The elemental composition of the ash residue (according to the iCAP 6300 Duo analyzer) was characterized by the highest content of silicon (39.0 wt.\%), calcium (28.9 wt.\%) and magnesium (14.6 wt.\%).

According to X-ray diffractometry data, the obtained biochar was characterized by an amorphous structure.

\subsection{Arc discharge synthesis}

Typical X-ray patterns of the products synthesized by electric arc method by $\left(\mathrm{C}_{\text {charcoal }}+\mathrm{SiO}_{2}\right)$ treatment are shown in Figure 1. In Figure 1a the diffraction patterns were corresponded to the samples obtained in a series of experiments with a different duration of the synthesis varied in the range from $5 \mathrm{~s}$ to $25 \mathrm{~s}$ (which corresponded to the amount of supplied energy from $30 \mathrm{~kJ}$ to $150 \mathrm{~kJ}$ ). The diffraction pattern (1, Figure 1, a) was typical for samples obtained with a synthesis process duration from $5 \mathrm{~s}$ to $10 \mathrm{~s}$. In the diffraction pattern an amorphous halo was identified in the $2 \bigotimes$ range from 16 deg. to $25 \mathrm{deg}$. which indicates the presence of an amorphous fraction in the synthesis product. The amorphous fraction could be referred to both biochar and amorphous silicon dioxide. The crystalline component was represented by two phases: graphite and a cubic phase of SiC. The lattice parameters of the graphite phase were the following: $a=2.465 \AA, c=6.871 \AA$. The lattice parameter of the cubic phase of silicon carbide was estimated as $a=4.354 \AA$. The diffraction patterns $(2$, Figure $1, a)$ and $(3$, Figure 1 , a) were characteristic for the synthesis products obtained with the duration of the arc discharge from 15 to $25 \mathrm{~s}$. Their characteristic feature was the absence of an amorphous halo. This could be an evidence of the initial amorphous biochar graphitization as well as the consumption of silicon dioxide during the 
silicon carbide formation. It should be noted that with an increase in the duration of the arc discharge, the energy consumption for the synthesis process was increased as well as the anode in the process of its consumption, which was also increased the amount of graphite contaminating the synthesis product [28]. Thus, it was experimentally established that for the complete processing of the feedstock the required arc discharge duration at current of 220 A must be 15 - 20 seconds. Further experiments with a change in the $\mathrm{SiO}_{2}: \mathrm{C}$ mass ratio were carried out with a synthesis process duration of $20 \mathrm{~s}$. Figure 1,b shows the results of this experimental series. All X-ray diffraction patterns were characterized by the presence of two crystalline phases: graphite and a cubic phase of silicon carbide. In this case, with an increase in the mass ratio of $\mathrm{SiO}_{2}: \mathrm{C}$, the intensity of the diffraction maxima corresponding to the silicon carbide phase was also increased. The largest ratio used was $\mathrm{SiO}_{2}: \mathrm{C}=3: 1$. A further increase in the proportion of silicon dioxide was seen as inappropriate, since the volume occupied by biochar in the composition of the initial components, which served as a matrix for the formation of the possible desired microstructure, was too small in comparison with the volume of the initial silicon oxide and gel based on it.

a) synthesized products obtained at different electric arc discharge durations:

1) $5-10 \mathrm{~s}$, 2) $15 \mathrm{~s}$, 3) $20-25 \mathrm{~s}$; b) typical diffraction patterns of the synthesis products obtained at the $20 \mathrm{~s}$ arc discharge duration at various mass ratios of the silicon dioxide to carbon in the initial mixture: 4) $\left.\left.\mathrm{SiO}_{2}: \mathrm{C}=1: 2,5\right) \mathrm{SiO}_{2}: \mathrm{C}=1: 1,6\right) \mathrm{SiO}_{2}: \mathrm{C}=3: 1$.

The experimental data obtained corresponded to the known concept of the silicon carbide synthesis in electric arc. Silicon dioxide $\mathrm{SiO}_{2}$ was placed in the zone of initiation and combustion of the arc discharge. It was decomposed, thus, due to the influence of high temperatures and was losing oxygen atoms with the silicon carbide formation under reaction (1). The evolved oxygen and air oxygen were reacted with carbon with the release of carbon monoxide $\mathrm{CO}$ under reaction (2). Carbon monoxide $\mathrm{CO}$ was further oxidized to form carbon dioxide $\mathrm{CO}_{2}$ (reaction (3)). The formation of $\mathrm{SiO}$ is also possible under reaction (4), but the yield of volatile silicon oxide is low under atmospheric pressure.

$\mathrm{SiO}_{2}+\mathrm{C} \circledast \mathrm{SiC}+\mathrm{O}_{2}$

$2 \mathrm{C}+\mathrm{O}_{2}{ }^{\circledR} 2 \mathrm{CO}$

$2 \mathrm{CO}+\mathrm{O}_{2}{ }^{\circledR} 2 \mathrm{CO}_{2}$

$\mathrm{SiO}_{2}{ }^{\circledR} \mathrm{SiO}+0.5 \mathrm{O}_{2}$

$\mathrm{CO}$ and $\mathrm{CO}_{2}$ formed a gaseous layer that protected the synthesized product $\mathrm{SiC}$ from oxidation by atmospheric oxygen. A similar explanation for the synthesis of silicon carbide was given in [29] which described a method for obtaining silicon carbide nanorods in constant current arc discharge plasma in a helium atmosphere. The dynamics of the $\mathrm{CO}$ and $\mathrm{CO}_{2}$ release with the formation of a protective gas barrier during the synthesis process was described in our previous work [24]. Thus, we can conclude that 
when synthesizing silicon carbide in an electric arc discharge plasma, regardless of the composition of a gaseous medium, the synthesis takes place in a protective atmosphere of $\mathrm{CO}$ and $\mathrm{CO}_{2}$.

However, just a low yield of the silicon carbide phase (10-15 wt.\%) according to the method of quantitative XRD was determined. It is known that silicon carbide is highly resistant to oxidation in air. Thus, we investigated the possibility of graphite removing from the synthesis products by calcination in an atmospheric furnace with the transition of carbon to gaseous $\mathrm{CO}_{2}$. A differential thermal analysis was carried out to choose the heating mode of the obtained materials.

The results of the oxidation process of a typical produced powder via the DTA-TG method are shown in Figure 2. The mass loss of the studied sample was proceeded in one stage, which was associated with the oxidation of graphite phase particles in the composition of the synthesis product. Since the sample was subjected to high-temperature treatment at the stage of synthesis, there was no stage of the adsorbed moisture removal (which is typical for biochar obtained by the method of steam gasification). The temperature of the onset of intense oxidation was about $700{ }^{\circ} \mathrm{C}$. The total mass loss of the sample was $84 \mathrm{wt} . \%$, which was observed in the temperature range $620-940^{\circ} \mathrm{C}$. Even though the ash content in the initial sample was about $1 \mathrm{wt} . \%$ (Table 1), the residue obtained after the oxidation in an amount of 16 wt.\% was associated with the cubic silicon carbide phase presence. The mass loss was recorded in the temperature range $700-900{ }^{\circ} \mathrm{C}$.

According to DTG data (Figure 2), the oxidation process of the studied sample was characterized by a monomodal peak, the maximum reaction rate in this point was $0.62 \mathrm{wt} . \% / \mathrm{min}$ at the $\mathrm{T}_{\max }=895^{\circ} \mathrm{C}$.

It should be noted that the position of the exothermic maximum on the DSC profile (Figure 2) was coincided with the value of $\mathrm{T}_{\max }$ corresponding to the maximum rate of the oxidation reaction (calculated from the DTG data). The observed exothermic effect was associated with the release of heat during the oxidation of the graphite phase.

According to the data of scanning electron microscopy combined with an energy dispersive analysis, the synthesis product mainly consisted of carbon (up to $51 \mathrm{wt}$ \%), oxygen (up to $22 \mathrm{wt}$.\%), silicon (up to 18 $w t . \%)$. The presence of trace amounts of other of chemical elements such as calcium was observed as well. The identification of impurities in the synthesis product, in particular, calcium, was explained by their presence in the composition of the obtained biochar. The dominance of carbon in the sample according to the data of energy dispersive analysis is natural due to the dominance of the graphite phase in the synthesis product. The relatively high oxygen content could be associated with its presence in the initial biochar, incomplete processing of the initial silicon dioxide, and the presence of an amorphous oxide shell on the surface of silicon carbide particles. The formation of an amorphous oxide layer on the surface of micro- and nanoparticles of silicon carbide is a well-known phenomenon, and is characteristic for materials both obtained by electric arc discharge plasma in atmospheric air [23] or inert gas [30-32].

Scanning electron microscopy was carried out using several different detectors: the BSE (back-reflected electrons) images obtained are given in Figure $3(a, c, d, f)$ and the SE (reflected electrons) the images are 
given in Figure $3(b, e)$. According to the data of scanning electron microscopy, the obtained silicon carbide was represented by both crystal shapes of regular outlines of flattened habit (typical for micronsized silicon carbide crystals [33]) and complex shapes obtained by the authors for the first time in the framework of a vacuum-free electric arc method. These structures were different from the traditional because of their porous structure, which had a certain similarity in textural features with the initial biochar material. On Figure 3 the number 1 indicates the porous and capillary structures of charcoal; number 2 denotes agglomerates of silicon dioxide particles deposited on the surface of charcoal; number 3 denotes silicon carbide structures. Structures of silicon carbide is indicated on Figure $3 \mathrm{~d}$, e. SiC phase, thus, was isolated from the synthesis product by the annealing in an atmospheric furnace and it had the morphological similarities with silicon carbide identified as biomorphic SiC [1]. The porous structure of the material obtained had a certain regularity and order which allowed us to conclude that the experiment with the synthesis of the biomorphic silicon carbide was successful.

\subsection{SiC purification and SPS treatment}

To isolate the phase of silicon carbide from the synthesis products, considering the data of differential thermal analysis, a heat treatment regime was chosen for annealing of the synthesis products. The samples were placed in an atmospheric oven, heated up to $850^{\circ} \mathrm{C}$ and held at this temperature for 2 hours. The materials obtained in this way were analyzed by XRD. XRD patterns of synthesis products purified from the graphite phase are shown on Figure 4a. The X-ray diffraction pattern on Figure $4 a$ corresponded to a sintered ceramic sample. The material consisted of silicon carbide only within the sensitivity limits of the XRD method. The lattice parameter of the main phase of silicon carbide in the obtained sample was $4.359 \AA$, which coincides with the lattice parameter of the reference phase of silicon carbide. This trace of the diffraction maximum at $2 \nabla=34.06$ might correspond to the presence of an insignificant amount of the hexagonal phase of a-SiC in the product [20]. According to EDX measurements, the sintered ceramic sample contained on average $34.1 \mathrm{wt} . \%$ of carbon, 62.4 at.\% of silicon, $3.0 \mathrm{wt}$ \% of oxygen and other chemical elements with a total content up to $0.5 \mathrm{wt} . \%$. As it was mentioned above, elemental oxygen could contain a thin X-ray amorphous oxide layer of ceramic sample. At the same time, energy dispersive analysis (taken from individual crystals from the image in Fig. 4b with dimensions of about $10 \mu \mathrm{m}$ ) showed that the mass ratio of silicon and carbon was within 1.7-1.9, and the oxygen content tended to a value close to zero. Judging by the data of scanning electron microscopy, the structure of the ceramic sintered sample was inhomogeneous. Pores with sizes of up to several micrometers were observed. The presence of these pores was the causes of the relatively low density $\sim 2.0 \mathrm{~g} / \mathrm{cm}^{3}$ of the sintered bulk sample.

\section{Conclusion}

In this work powders and a ceramic sample of SiC were obtained using the electric arc method for plasma processing a mixture of silicon oxide and charcoal obtained from sawdust. The dependences of the phase composition of the synthesis product from the initial parameters of the process, in particular, duration of the synthesis and the silicon dioxide to charcoal mass ratio, were obtained. By annealing the 
obtained material in an atmospheric furnace at $850^{\circ} \mathrm{C}$, it was possible to purify the phase of cubic silicon carbide from the graphite. The resulting powder was sintered by SPS method. Ceramic sample was characterized by the rather low density $\sim 2.0 \mathrm{~g} / \mathrm{cm}^{3}$. The morphology of the obtained materials was made it possible to identify multiple pores and individual crystals of silicon carbide with size varied in a range from 1 to $10 \mu \mathrm{m}$. The similar to biomorphic silicon carbide structures could be found into obtained powder material.

Thus, the article revealed the possibility of obtaining a SiC powder with a biomorphic structure, as well as low-density ceramics based on silicon carbide using charcoal. The vacuum-free electric arc method was used which was realized in an ambient air environment. Cubic silicon carbide was synthesized for the first time using charcoal (obtained from woodworking waste) and silicon oxide in atmospheric electric arc plasma by a non-vacuum method.

\section{Declarations}

Funding: This research was supported by TPU development program.

Conflicts of interest/Competing interests: The authors declare that they have no known conflict or competing financial interests or personal relationships that could have appeared to influence the work reported in this paper.

Availability of data and material: Data available within the article or its supplementary materials

\section{Authors' contributions:}

Alexander Ya. Pak - direct current plasma arc processing of samples, writing - original draft;

Kirill B. Larionov - wood waste biochar samples acquisition and characterization;

Anastasia P. Korchagina - XRD data acquisition and interpretation, plasma arc processing data analysis;

Tamara Yu. Yakich - SEM and EDS results acquisition and interpretation;

Stanislav A. Yankovsky - DTA-TG data acquisition and interpretation;

Vladimir E. Gubin - idea and design of article, general supervision;

Konstantin V. Slyusarskiy - writing;

Alexander A. Gromov - review \& editing.

\section{References}


1. Yu, M., Zhang, G.J., Saunders, T.: Wood-derived ultra-high temperature carbides and their composites: A review. Ceram. Int. 46, 5536-5547 (2020). https://doi.org/10.1016/j.ceramint.2019.11.104

2. Jayakumari, S., Vullum, P.E., van Helvoort, A.T.J., Tangstad, M.: SiC crystalline micro bullets on biocarbon based charcoal substrate. J. Cryst. Growth. 545, 125740 (2020). https://doi.org/10.1016/j.jcrysgro.2020.125740

3. Kaarik, M., Arulepp, M., Kook, M., Kozlova, J., Ritslaid, P., Aruvali, J., Maeorg, U., Sammelselg, V., Leis, J.: High-performance microporous carbon from deciduous wood-origin metal carbide. Microporous Mesoporous Mater. 278, 14-22 (2019). https://doi.org/10.1016/j.micromeso.2018.11.010

4. Gomez-Martín, A., Orihuela, M.P., Becerra, J.A., Martinez-Fernandez, J., Ramirez-Rico, J.: Permeability and mechanical integrity of porous biomorphic $\mathrm{SiC}$ ceramics for application as hot-gas filters. Mater. Des. 107, 450-460 (2016). http://dx.doi.org/10.1016/j.matdes.2016.06.060

5. Kormann, M., Gerhard, H., Popovska, N.: Comparative study of carbide-derived carbons obtained from biomorphic TiC and SiC structures. Carbon. 47, 242-250 (2009).

https://doi.org/10.1016/j.carbon.2008.10.002

6. Kim, J.W., Myoung, S.W., Kim, H.C., Lee, J.H., Jung, Y.G., Jo, C.Y.: Synthesis of SiC microtubes with radial morphology using biomorphic carbon template. Mater. Sci. Eng. A. 434, 171-177 (2006). https://doi.org/10.1016/j.msea.2006.06.135

7. Qian, J., Wang, J., Hou, G., Qiao, G., Jin, Z.: Preparation and characterization of biomorphic SiC hollow fibers from wood by chemical vapor infiltration. Scripta Mater. 53, 1363-1368 (2005). https://doi.org/10.1016/j.scriptamat.2005.08.029

8. Lee, D.J., Jang, J.J., Park, H.S., Kim, Y.C., Lim, K.H., Park, S.B., Hong, S.H.: Fabrication of biomorphic $\mathrm{SiC}$ composites using wood preforms with different structures. Ceram. Int. 38, 3089-3095 (2012). https://doi.org/10.1016/j.ceramint.2011.12.008

9. Streitwieser, D.A., Popovska, N., Gerhard, H., Emig, G.: Application of the chemical vapor infiltration and reaction (CVI-R) technique for the preparation of highly porous biomorphic SiC ceramics derived from paper. J. Eur. Ceram. Soc. 25, 817-828 (2005).

https://doi.org/10.1016/j.jeurceramsoc.2004.04.006

10. Pappacena, K.E., Gentry, S.P., Wilkes, T.E., Johnson, M.T., Xie, S., Davis, A., Faber, K.T.: Effect of pyrolyzation temperature on wood-derived carbon and silicon carbide. J. Eur. Ceram.Soc. 29, 30693077 (2009). https://doi.org/10.1016/j.jeurceramsoc.2009.04.040

11. Qian, J., Wang, J., Jin, Z.: Preparation of biomorphic SiC ceramic by carbothermal reduction of oak wood charcoal. Mater. Sci. Eng. A. 371, 229-235 (2004).

https://doi.org/10.1016/j.msea.2003.11.051

12. Presas, M., Pastor, J.Y., Llorca, J., Arellano Lopez, A.R., Martınez Fernandez, J., Sepulveda, R.: Microstructure and fracture properties of biomorphic SiC. Int. J. Refract. Met. Hard Mater. 24, 49-54 (2006). https://doi.org/10.1016/j.jjrmhm.2005.07.003

13. Bautista, M.A., Quispe Cancapa, J., Martinez Fernandez, J., Rodriguez, M.A., Singh, M.: Microstructural and mechanical evaluation of porous biomorphic silicon carbide for high 
temperature filtering applications. J. Eur. Ceram. Soc. 31, 1325-1332 (2011).

https://doi.org/10.1016/j.jeurceramsoc.2010.06.014

14. Li, J., Yu, S., Ge, M., Wei, X., Qian, Y., Zhou, Y., Zhang, W.: Fabrication and characterization of biomorphic cellular C/SiC-ZrC composite ceramics from wood. Ceram. Int. 41, 7853-7859 (2015). http://dx.doi.org/10.1016/j.ceramint.2015.02.122

15. Borrajo, J.P., Serra, J., Liste, S., Gonzalez, P., Chiussi, S., Leon, B., Perez-Amor, M.: Pulsed laser deposition of hydroxylapatite thin films on biomorphic silicon carbide ceramics. Appl. Surf. Sci. 248, 355-359 (2005). https://doi.org/10.1016/j.apsusc.2005.03.051

16. Hou, G., Jin, Z., Qian, J.: Effect of starting Si contents on the properties and structure of biomorphic SiC ceramics. J. Mater. Process. Technol. 182, 34-38 (2007).

https://doi.org/10.1016/j.jmatprotec.2006.07.003

17. Pavon, J.M.C., Alonso, E.V., Cordero, M.T.S., Torres, A.G.B., López-Cepero, J.M.: Use of spectroscopic techniques for the chemical analysis of biomorphic silicon carbide ceramics. Anal. Chim. Acta. 528, 129-134 (2005). https://doi.org/10.1016/j.aca.2004.09.090

18. Qian, J.M., Wang, J.P., Qiao, G.J., Jin, Z.H.: Preparation of porous SiC ceramic with a woodlike microstructure by sol-gel and carbothermal reduction processing. J. Eur. Ceram. Soc. 24, 3251-3259 (2004). https://doi.org/10.1016/j.jeurceramsoc.2003.10.042

19. Wu, H., Zhang, T., Li, Y.: Fabrication of biomorphic ZrC/C ceramics by sol-gel and carbothermal reduction processing. Ceram. Int. 41, 13034-13041 (2015).

http://dx.doi.org/10.1016/j.ceramint.2015.07.004

20. Li, Y., Xie, S., Wei, B., Lian, G., Zhou, W., Tang, D., Zou, X., Liu, X., Wang, G.: Aligned small a-SiC nanorods on $\beta$-SiC particles grown in an arc-discharge. Solid State Commun. 119, 51-53 (2001). https://doi.org/10.1016/S0038-1098(01)00196-X

21. Li, Y.B., Xie, S.S., Zou, X.P., Tang, D.S., Liu, Z.Q., Zhou, W.Y., Wang, G.: Large-scale synthesis of $\beta$-SiC nanorods in the arc-discharge. J. Cryst. Growth. 233, 125-128 (2001). https://doi.org/10.1016/S0022-0248(01)00597-8

22. Chiu, S.C., Huang, C.W., Li, Y.Y.: Synthesis of High-Purity Silicon Carbide Nanowires by a Catalyst-Free Arc-Discharge Method. J. Phys. Chem. C. 111, 10294-10297 (2007). https://doi.org/10.1021/jp0687192

23. Pak, A., Ivashutenko, A., Zakharova, A., Vassilyeva, Y.: Cubic SiC nanowire synthesis by DC arc discharge under ambient air conditions. Surf. Coat. Technol. 387, 125554 (2020). https://doi.org/10.1016/j.surfcoat.2020.125554

24. Pak, A., Shanenkov, I., Mamontov, G., Kokorina, A.: Vacuumless synthesis of tungsten carbide in a self-shielding atmospheric plasma of DC arc discharge. Int. J. Refract. Met. Hard Mater. 93, 105343 (2020). https://doi.org/10.1016/j.jijrmhm.2020.105343

25. Su, Y., Wei, H., Li, T., Geng, H., Zhang, Y.: Low-cost synthesis of single-walled carbon nanotubes by low-pressure air arc discharge. Mater. Res. Bull. 50, 23-25 (2014). http://dx.doi.org/10.1016/j.materresbull.2013.10.013 
26. Joseph Berkmans, A., Jagannatham, M., Rohit Reddy, D., Haridoss, P.: Synthesis of thin bundled single walled carbon nanotubes and nanohorn hybrids by arc discharge technique in open air atmosphere. Diamond Relat. Mater. 55, 12-15 (2015).

http://dx.doi.org/10.1016/j.diamond.2015.02.004

27. Zhao, J., Wei, L., Yang, Z., Zhang, Y.: Continuous and low-cost synthesis of high-quality multi-walled carbon nanotubes by arc discharge in air. Physica E Low Dimens. Syst. Nanostruct. 44, 1639-1643 (2012). http://dx.doi.org/10.1016/j.physe.2012.04.010

28. Arora, N., Sharma, N.N.: Arc discharge synthesis of carbon nanotubes: Comprehensive review. Diamond Relat. Mater. 50, 135-150 (2014). http://dx.doi.org/10.1016/j.diamond.2014.10.001

29. Chiu, S.C., Huang, C.W., Li, Y.Y.: SiC Nanowires by a Catalyst-Free Arc-Discharge Method. J. Phys. Chem. C. 111, 10294-10297 (2007). https://doi.org/10.1021/jp0687192

30. Liang, C.H., Meng, G.W., Zhang, L.D., Wu, Y.C., Cui, Z.: Large-scale synthesis of b-SiC nanowires by using mesoporous silica embedded with Fe nanoparticles. Chem. Phys. Lett. 329, 323-328 (2000). https://doi.org/10.1016/S0009-2614(00)01023-X

31. Yang, W., Araki, H., Thaveethavorn, S.H., Suzuki, T., Noda: In situ synthesis and characterization of pure SiC nanowires on silicon wafer. Appl. Surf. Sci. 241, 236-240 (2005).

https://doi.org/10.1016/j.apsusc.2004.09.039

32. Hao, Y.J., Jin, G.Q., Han, X.D., Guo, X.Y.: Synthesis and characterization of bamboo-like SiC nanofibers. Mater. Lett. 60, 1334-1337 (2006). https://doi.org/10.1016/j.matlet.2005.10.115

33. Eom, J.H., Kim, Y.W., Song, I.H.: Effects of the initial-SiC content on the microstructure, mechanical properties, and permeability of macroporous silicon carbide ceramics. J. Eur. Ceram. Soc. 32, 12831290 (2012). https://doi.org/10.1016/j.jeurceramsoc.2011.11.040

\section{Figures}
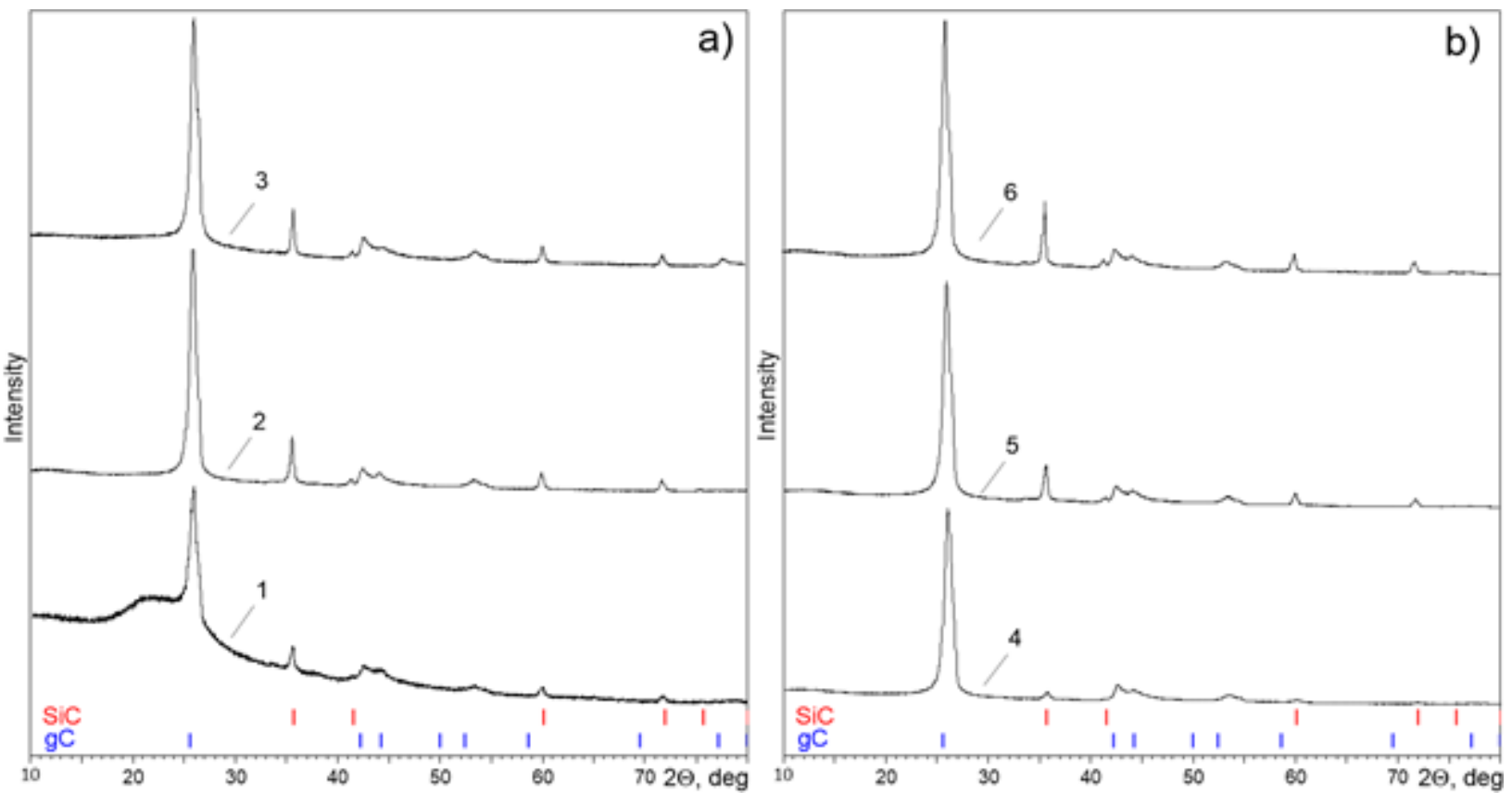

Page 13/16 
Figure 1

XRD patterns of the obtained products $(\lambda=1.54060 \AA)$ : a) synthesized products obtained at different electric arc discharge durations: 1) 5-10 s, 2) $15 \mathrm{~s}, 3) 20-25 \mathrm{~s}$; b) typical diffraction patterns of the synthesis products obtained at the $20 \mathrm{~s}$ arc discharge duration at various mass ratios of the silicon dioxide to carbon in the initial mixture: 4) $\mathrm{SiO} 2: \mathrm{C}=1: 2,5) \mathrm{SiO}: \mathrm{C}=1: 1,6) \mathrm{SiO}: \mathrm{C}=3: 1$.

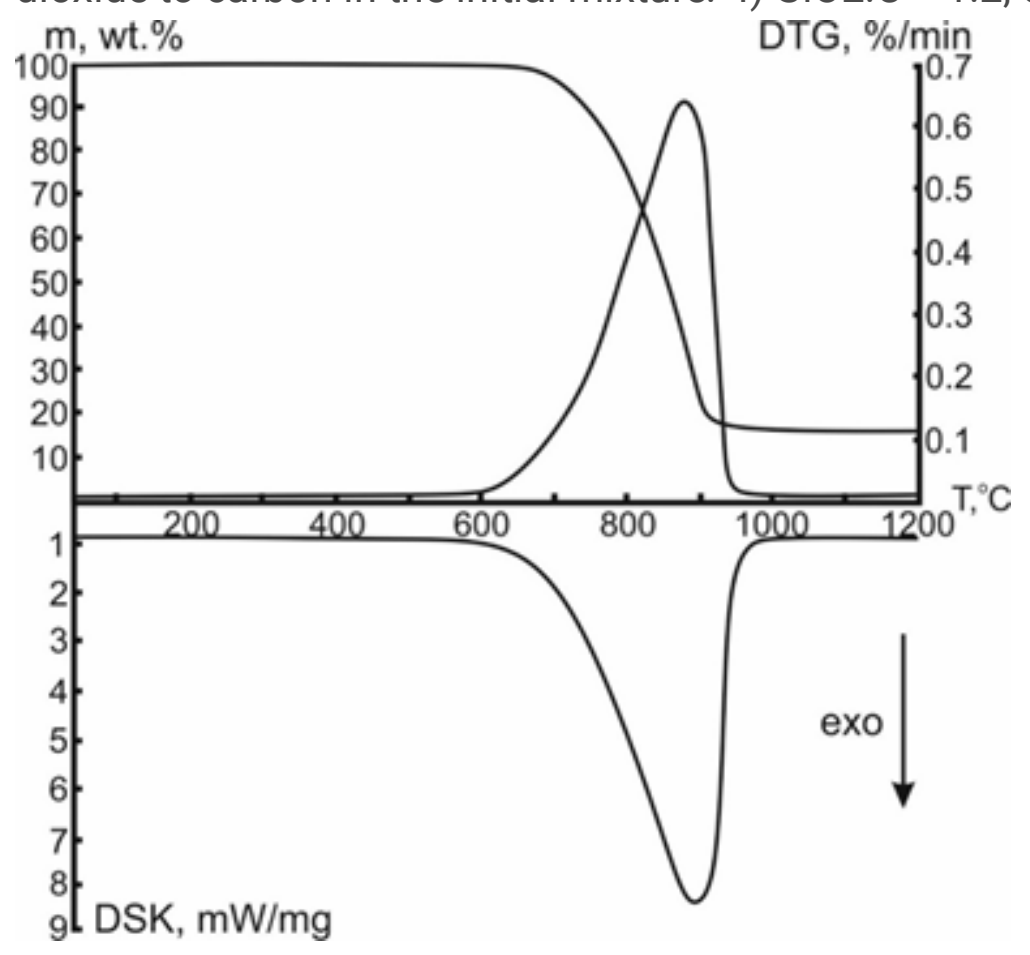

Figure 2

TG, DTG and DSC data for the oxidation process of the as-synthesized product $(\mathrm{SiC}+\mathrm{C})$. Air flow rate 150 $\mathrm{ml} / \mathrm{min}$, heating rate $10^{\circ} \mathrm{C} / \mathrm{min}$, sample weight $20 \mathrm{mg}$. 


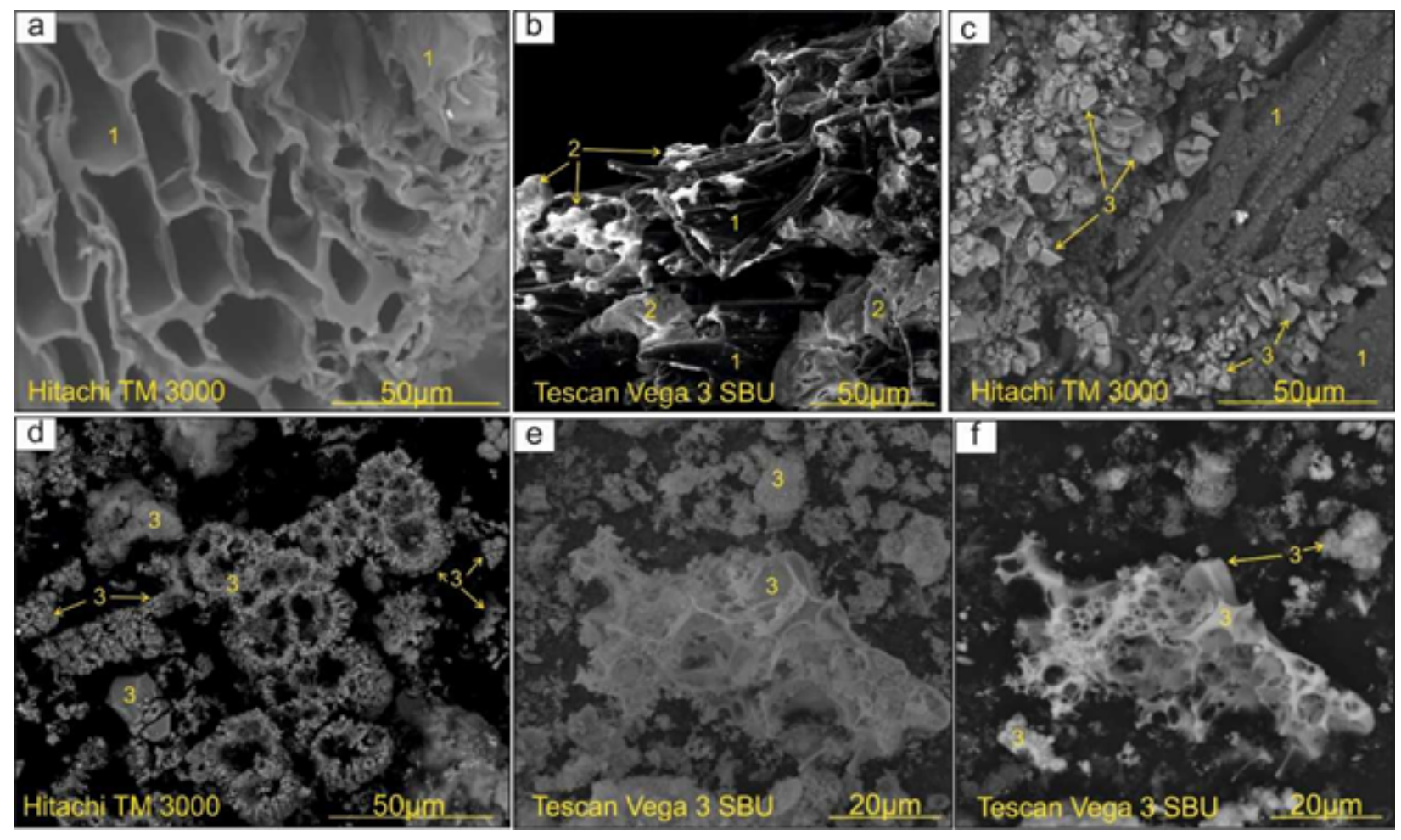

\section{Figure 3}

SEM images of initial raw materials and products of electric arc synthesis: a) initial material - charcoal (1); b) precursor for the synthesis of biomorphic silicon carbide, which was a mixture of charcoal (1) (dark color) and silicon dioxide (2) (white); c) crystals of silicon carbide (3), obtained as a result of plasma treatment of the precursor (b) before annealing; $d-f$ ) silicon carbide after annealing of the sample (c) in the form of idiomorphic crystals (d) and complex aggregates (d-f), reflecting the porous structure of the original sawdust material (1). 

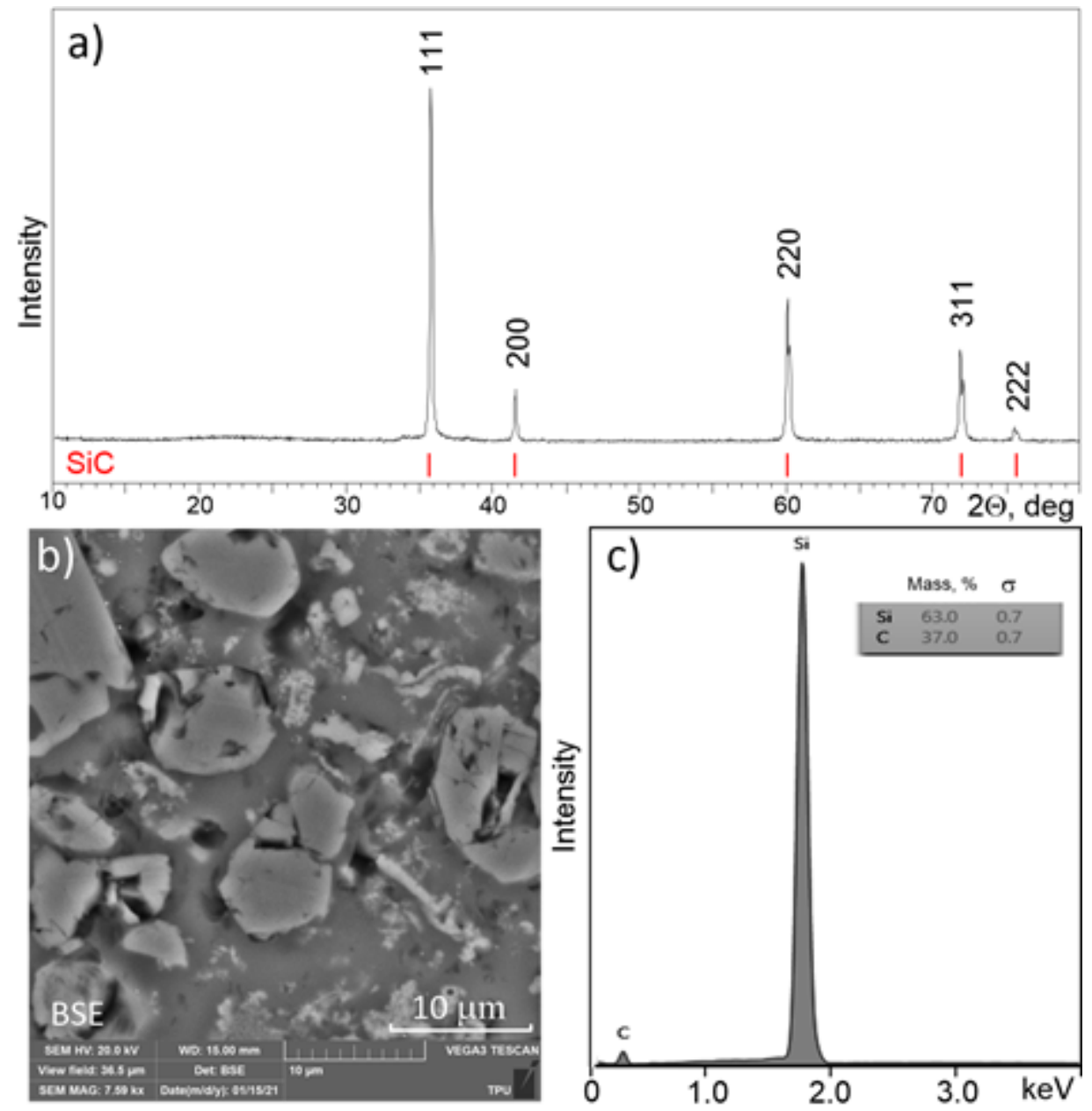

Figure 4

Sintered ceramics analysis results: a) XRD pattern of the synthesis products after purification and sintering; b) SEM image if the surface; c) corresponding EDX.

\section{Supplementary Files}

This is a list of supplementary files associated with this preprint. Click to download.

- Video1.gif

- Video2.gif

- GA.png 